\title{
Summer Research Appointments at Federal Research Laboratories
}

\section{Robert A. Lucas}

California Polytechnic State University

Some faculty members in science and engineering departments need help getting their research careers started. Often, a summer appointment at a federal research laboratory can give them the boost they need to launch a fledgling career. These opportunities may provide the experience faculty members need to write a paper, improve their track record, or write a successful grant proposal. The National Atmospheric and Space Administration, the Department of Defense, the Department of Energy, and the National Science Foundation all have programs that support summer faculty programs at federal research laboratories.

Experience tells us that no matter what criteria campuses publish, most often it is research, not teaching, that receives priority in consideration for promotion, retention, and tenure. At comprehensive universities, faculty members do not have the lighter teaching loads or more sophisticated facilities offered at research universities. For them, getting started in research is difficult. Once they have finished mining their dissertation for publishable articles and have written proposals for the research competitions that are restricted to new faculty, they have few other special opportunities to help them launch their careers.

If this problem is a difficult one for new faculty members, it is even more so for the established faculty at the comprehensive university. Many of the latter came to the institution because they were primarily interested in teaching. Many now find themselves expected to do some research as well. But they have been away from the cutting edge of the discipline too long to get back to it easily, and they can no longer submit proposals for competitions restricted to the recent Ph.D. 
To get started, these faculty members need an externally funded research grant. Their institution might give them a small seed grant to do some preliminary work, but pilot studies can do little more than establish the feasibility of the proposed project. To be funded, proposals need the credibility only publications on a curriculum vitae can offer. Faculty simply cannot write a competitive proposal for a research grant unless they can demonstrate currency through peer-reviewed publication.

\section{Summer Research for New and Established Faculty}

Fortunately, there is a single solution for both new and research re-entry faculty. Many federal agencies have mini-programs directed towards faculty at four- and five-year institutions to support them for a substantial period - a summer and sometimes more - while they conduct research at a major federal research laboratory. During these appointments, visiting faculty work on ongoing research topics at the laboratory, have full access to the laboratory's state-of-the-art equipment, and often complete enough work to be involved in some publications. In many instances, they can repeat these appointments once or twice and thus develop a modest track record before applying for research grants on their own.

A number of federal agencies offer faculty research participation programs. These include the National Science Foundation, the National Atmospheric and Space Administration, the Department of Defense, and the Department of Energy. Each agency works somewhat differently, but most require that the faculty member initiate the enterprise by contacting a researcher in a laboratory and working out the details of the research collaboration before a request is sent to the granting agency.

The requirement for advance contact with the lead researcher at the laboratory personalizes the process. A phone call is less threatening than sending a full proposal out for formal competitive review. These discussions can help new faculty members or returning researchers gauge in advance what their chances of support are.

In most cases, chances for support are much greater than in the competitive grants world. Nationally, only about one of every three or four proposals is funded. But in research participation programs, about one of every two applications is funded. The higher funding ratio is encouraging to new faculty and established faculty alike. The relative accessibility of 
these grants makes them worth promoting among science and engineering faculty who have anxieties about their career development.

\section{Research Opportunity Award Program}

The Research Opportunity Award (ROA) program at the National Science Foundation (NSF) serves as a good example of how the program works. The ROA is intended to strengthen faculty who have limited access to sophisticated research instrumentation. Faculty members contact the principal investigator of an NSF grant at a research university and ask if he or she would be interested in having a collaborator for the summer. If the offer is agreeable, the principal investigator sends an ROA grant supplement request to NSF to support the visiting scholar. Paperwork is minimal, and, compared to other NSF competitions, chances for success are high.

A professor of physics at our institution applied successfully for one of these awards over ten years ago. When he arrived at the laboratory for the summer, his host told him the lab was his to use as he pleased. With no research agenda to restrict him, the professor spent the time sitting and staring at data and charts and wondering about the current theories in his field. When the two months were over, he had begun to reconceptualize completely his thinking about prehistoric changes in the polarity of the earth's magnetic field. Those thoughts led to a series of successful studies, papers, and grants. Ten years later, his reconceptualization has become the dominant theory in his field.

\section{Benefits of the Research Opportunity Award Program}

A study of the NSF program completed in the early 1980's showed that benefits to faculty were great. Over half of the awards in the previous five years were given to faculty at comprehensive universities. Faculty who participated described the experience as "invaluable personal development," "a good professional boost," and "rejuvenating" (Razvi, 1984).

Benefits to instruction were also significant. Razvi reported that faculty members said they were more enthusiastic about their regular teaching responsibilities, that they improved course content and quality of instruction, that students gained valuable research experience, and that the papers they published and the grants they won helped their institutions achieve greater status. 


\section{DOE Cooperative Laboratory Research Program}

The U.S. Department of Energy (DOE) has one of the most extensive summer faculty research programs. Through four regional university consortia, it places faculty in over $\mathbf{5 0}$ laboratories conducting energy research. Research facilities include Oak Ridge National Laboratory, Argonne National Laboratory, the Solar Energy Research Institute, the Stanford Linear Accelerator Center, and the Lawrence Berkeley Laboratory. Not all of the $\mathbf{5 0}$ laboratories are dedicated energy laboratories, but each has at least one unit doing significant energy research.

The DOE program aims to update faculty in their field so they can improve curricula at their home institution and facilitate the transfer of technology from the laboratories to the work place. The major disciplines include engineering, physics, chemistry, and environmental, health, and life sciences. In addition to its impact on the curriculum, a major benefit of the program is participants' success in developing continuing relationships with the energy laboratories.

A recent study showed that past participants in this program are 33 percent more likely to be involved in federally-funded research than faculty who have not participated (Stevenson, 1988). Upon completing a summer or a semester in one of the energy laboratories, 70 percent of the faculty reported writing a proposal for research support after they returned to their home institution. Two out of five of these proposals were successful. Over 80 percent of the participants said that following the appointment at the laboratory, there was at least some limited continuing relationship with the federal research laboratory. Fifty percent said that relationship was significant.

\section{Summer Appointments Can Revive Research Careers}

The impact of the DOE on participants' research careers was important, as the following statements by some participants show:

I teach in an institution which emphasizes teaching as our primary mission. Consequently, we do not have the time or qualified students to support ... research. Therefore, an opportunity to carry on research at Jet Propulsion Lab ... was very helpful to me. The advantages are many: work on an interesting problem (silicon solar cell), work with modern equipment, work with other research scientists, publication of our 
results, financial compensation, and continuation of research after the summer.... The DOE program revived my research career.

[This program has] been the biggest boost to my career since leaving graduate school. My experience in summer 1979 led to my spending my sabbatical year ... at Argonne. The enclosed list of publications largely comes from a two-year-long development of an animal model for cadmium toxicology that I was able to construct while at Argonne. My collaboration with Argonne will eventually produce about 15 papers. Not too shabby!

My summer experiences at Oak Ridge and more recently at Savannah Research Laboratory have brought me up to date in my area of training and have enabled me to advance to the rank of full professor more rapidly than otherwise. In addition, I have been able to obtain consulting work through my contacts at these two laboratories that otherwise would probably not have occurred.

The impact on the curriculum is extensive as well. Nearly 80 percent of the faculty said that upon their return to the campus, they revised their course offerings; 70 percent indicated they changed their laboratory experiments. Typical comments were as follows:

As a result of my two summers at Battelle, I have taught one course each year dealing with cancer and chemical carcinogenesis... Several of the lab techniques I learned have become incorporated (in a modified form) into several of the upper-division labs I periodically teach.

Another consequence of my participation in the Faculty Research Participation Program has been the benefits to my students at my home institution. I have been better able to instruct them in the significance and application of recent research in biochemistry and cell biology. I have learned techniques that have been applied in the undergraduate teaching laboratories at the college. I also have been able to describe my own participation in research and make the nature of scientific endeavor more immediate and meaningful to my students.

Participation in the cooperative laboratory research program helps faculty become more productive professionally. In the study, 566 faculty responded to the survey questionnaire. Recent scholarly accomplishments of this group included 92 books, 263 book chapters, 656 reports, 3,700 journal articles, and 2,621 conference papers. Those who received funding to continue work with an energy laboratory were the most productive. 
Similar benefits were reported in a program supported by the National Atmospheric and Space Administration (NASA). The 151 faculty in the study reported 508 journal articles and 369 refereed papers. In addition, the summer research experience produced 122 new courses and changed, modified, or otherwise influenced 473 other courses.

\section{Three DOD Programs}

The Department of Defense (DOD) sponsors a number of summer research programs. They cover a broad range of topics and are intended to stimulate the development of mutual research interests between defense laboratories and universities. The faculty member spends a summer working at a defense research laboratory with the objective of developing a research project that can be continued at the home institution. These programs are funded through the Army Research Office, the Office of Naval Research, and the Air Force Office of Scientific Research.

Universal Energy Systems, Inc., which administers the contract for the Air Force, has studied the impact of the Air Force program (Darrah, 1988). In the summer of 1988,153 faculty were assigned to research laboratories and centers at 22 research sites. Over half of these faculty members subsequently won a Research Initiation Award of $\$ 20,000$ to continue their research at their home institutions after completion of the summer program.

The study questioned participants about their experiences at these facilities. Of 152 respondents, 109 rated the technical challenge of the summer research work as high; 115 found the probability for future research high; and 98 reported that the appointment definitely enhanced their research qualifications.

The research colleagues with whom the participants worked reported that in almost all cases, the summer experience improved faculty members' ability to perform research by exposing them to new research areas or by giving them increased experience in unfamiliar areas. More than a third of the researchers at these laboratories said the summer participants had advanced the laboratories' missions by contributing new methods, techniques, and viewpoints. 


\section{Common Characteristics of Summer Research Programs}

The programs described above comprise the major available opportunities. Most of these programs have the following characteristics:

1. The faculty member must make contact with an individual at the research laboratory. Thus, some advance knowledge by the faculty member about precisely where he or she wants to go is essential before the rest of the process can begin.

2. They offer small travel grants so that faculty can visit a laboratory and explore in greater detail the possibilities of collaboration.

3. Deadlines for formal applications are sprinkled throughout the fall and early winter, although facilities requiring security clearance take another nine months.

4. Summer support stipends often have a fixed ceiling and include travel expenses and some cost of living allowance. No indirect costs are paid to the campus.

5. Appointments are often repeated for a second summer, but seldom for a third or fourth.

\section{Options for Agencies without Formal Programs}

Many agencies that do not have special faculty programs can use a generic option through the Intergovernmental Personnel Act (IPA). This mechanism permits a federal office such as the Environmental Protection Agency to reimburse a university for a faculty member's full salary and expenses while he or she spends a summer or more working at the agency on projects of mutual interest. The IPA program is popular with federal agencies, because they can use it to acquire intensive and sustained consultation without straining their restricted personnel budgets.

\section{Role of the Faculty Developer}

Often faculty learn about these programs from their department chair or their grants development officer. If the campus has no organized grants office, the faculty development officer can help by learning about these programs. The addresses of the major programs are listed in the appendix. 


\section{Conclusion}

New faculty members in science and engineering or faculty members who have been out of the mainstream of science and technology research have ready access to the world of publication and funded research through summer appointments at major federal research laboratories. Many of these laboratories have specific programs that are designed explicitly to foster technology transfer, encourage research, and update the curriculum. Faculty members who take advantage of these opportunities find their teaching improved and their research qualifications enhanced.

\section{References}

Darrah, Rodney C., Espy, Susan K., \& Cavender, Claude. (1988). United States Air Force Summer Faculy Research Program: 1988 Program management report. Dayton: Universal Energy Systems.

Franco, Madeleine, \& Lucas, Robert A. (1985). Laboratory cooperative research: U.S. Department of Energy opportunities. Grants Magazine, 8, 109-113

Razvi, Aga. (1984). Research opportunities for small-college and university faculty. Grants Magazine, 7, 42-50.

Stevenson, Wayne, \& Vivio, Frank M. (1988). U.S. Department of Energy Faculy Research Participation Program: Profile and survey of 1979-1986 participants. Draft Report, November 21, 1988. Washington, DC: U.S. Department of Energy. 


\section{Appendix}

The following is a list of contacts for each of the major summer research participation programs.

Air Force

USAF Summer Faculty Research Program

Universal Energy Systems, Inc.

4401 Dayton-Xenia Road

Dayton, Ohio 45432-1894

\section{Army}

U.S. Army Summer Faculty Research and Engineering Program Battelle RTP Office

200 Park Drive

P.O. Box 12297

Research Triangle Park, North Carolina 27709

Department of Energy

Associated Universities

Office of Academic Relations

Building 460

Upton, Long Island, New York 11973

Associated Western Universities

4190 S. Highland Dr.

Suite 211

Salt Lake City, Utah 84124

Northwest College and University Association for Science 100 Sprout Road

Richland, Washington 99352

Oak Ridge Associated Universities

P.O. Box 117

Oak Ridge, Tennessee 37830 
National Aeronautics and Space Administration

NASA Summer Faculty Fellowship Program

American Society for Engineering Education

Eleven Dupont Circle, Suite 200

Washington, D.C. 20036

\section{National Science Foundation}

Research Opportunity Awards Program

Division of Research Initiation and Improvement

National Science Foundation

1800 G Street, N.W.

Washington, D.C. 20550

Navy

U.S. Navy-ASEE Summer Faculty Research Program American Society for Engineering Education

Eleven Dupont Circle, Suite 200

Washington, D.C. 20036 